\title{
Improvement of Thermal and Mechanical Properties of Vietnam Deproteinized Natural Rubber via Graft Copolymerization with Methyl Methacrylate
}

\author{
Thi Nhan Nguyen, Hieu Nguyen Duy, Dung Tran Anh, Thuong Nghiem Thi $\mathbb{D}$, \\ Thu Ha Nguyen, Nam Nguyen Van, Tung Tran Quang, Tung Nguyen Huy, \\ and Thuy Tran Thi
}

School of Chemical Engineering, Hanoi University of Science and Technology, No. 1 Dai Co Viet, Hanoi, Vietnam

Correspondence should be addressed to Thuy Tran Thi; thuy.tranthi3@hust.edu.vn

Received 5 April 2020; Revised 24 May 2020; Accepted 8 June 2020; Published 14 July 2020

Academic Editor: Mehdi Salami-Kalajahi

Copyright (c) 2020 Thi Nhan Nguyen et al. This is an open access article distributed under the Creative Commons Attribution License, which permits unrestricted use, distribution, and reproduction in any medium, provided the original work is properly cited.

In this study, we investigated the improvement of the thermal and mechanical properties of Vietnam deproteinized natural rubber (DPNR) via graft copolymerization of methyl methacrylate (MMA). The graft copolymerization was achieved successfully in latex stage using tert-butyl hydroperoxide (TBHPO) and tetra-ethylenepentamine (TEPA) as radical initiators at $30^{\circ} \mathrm{C}$. By grafting with various MMA feeds and initiator concentration of $6.6 \times 10^{-5} \mathrm{~mol} / \mathrm{g}$-rubber, the highest grafting efficiency and conversion were achieved at MMA of $15 \mathrm{wt} . \%$ per $\mathrm{kg}$ of rubber, $68 \%$ and $90 \%$, respectively. The structure of grafted copolymers was characterized by ${ }^{1} \mathrm{H}$ NMR, FTIR-ATR, and GPC, and thermal properties were investigated through DSC and TGA measurements. These showed that graft copolymers were more stable and rigid than DPNR. Storage modulus $\left(G^{\prime}\right)$ of graft copolymer was found to double that of DPNR, which contributed to the formation of graft copolymer. After sulfur vulcanization, the mechanical properties of DPNR-graft-PMMA, such as tensile strength, tear strength, and hardness, were improved significantly. Curing behaviors of the graft copolymers were found to be remarkably better than virgin DPNR.

\section{Introduction}

In recent years, environmental issues have become more important. As a result, the use and development of renewable materials as natural polymers are becoming a new trend in society. Natural rubber (NR) obtained from the Hevea Brasiliensis tree is considered to be a renewable resource and an environmentally friendly material [1]. Vietnam ranked third as NR producer as well as exporter in the world in 2017 [2]. Therefore, NR is an abundant green material and also an important resource of Vietnam's economy. Global demand for natural rubber has however increased rapidly in the past decade, driven particularly by China's economic emergence [3]. Additionally, the price of NR has fluctuated for more than a year due to some factors including climate conditions, which can directly affect NR's quality $[1,2,4,5]$. The recent rise of the global NR consumption has encouraged Vietnam as the main NR producing country to expand its expertise with rubber trees into a multipurpose crop for the national economic development. This will improve the social conditions of rural areas and lead to regreening bare land towards environmental protection. Besides various excellent physical properties, including high elasticity and high tensile strength, NR also has some undesirable properties such as low heat resistance and poor aging properties, as well as low oil resistance due to the low saturation degree of the molecular chain $[1,6-8]$. The quest for NR's practical applications led to the investigation into the enhancement of NR's properties. This also contributes to the sustainable management of natural resources by the development of highly functional polymers 
based on natural rubber and furthermore boots Vietnam's rubber industry [2].

To limit NR's drawbacks, many methods have been attempted from blending NR with other synthetic materials or adding fillers to chemical modification [9-13]. Efficient paths towards adding value to NR have been followed by incorporating new functional groups onto the natural polymer, chemical modification such as hydrogenation [14-17], epoxidation [18], and copolymerization with vinyl monomers over more than 50 years [3]. Among those, the graft copolymerization has received considerable interest from scientists, which is shown by the increasing number of studied monomers. In addition, different aspects of this modification have been examined recently. Some prominently used vinyl monomers are acrylonitrile (AN) [19], methyl methacrylate (MMA) [20-23], maleic anhydride (MA) [24], and styrene $[2,7,8]$. MMA and styrene are the most suitable for grafting with NR because of their high grafting efficiency. Due to the high polarity of MMA, the graft copolymer of NR will have outstanding prospects in the fields of adhesive and conducting polymer materials.

Thermal and mechanical properties of natural rubber are very important for its applications, since NR products are often exposed under real environmental conditions, including sunlight, UV irradiation, and high temperature. Therefore, it is necessary to improve NR properties as well as its thermal stability to widen its practical application. Among various monomers being grafted on NR, MMA is one of the precursors of thermoplastic polymer. Subsequently, the product, i.e., DPNR-graft-PMMA possesses good thermal stability and high resistance to heat and light. Hence, chemical modification of NR using MMA through graft copolymerization is promising for improving the mechanical and thermal properties of NR. However, in order to prolong the lifecycle for NR materials, vulcanization is necessary to be performed for NR. Thus, cure characteristics and properties of graft copolymer in vulcanized state are also an important aspect to apply the materials in human life.

In previous work, graft copolymerization of MMA onto NR's backbone has been studied for several years and is conducted via radical emulsion polymerization using redox initiators [25-27]. Potassium persulfate $\left(\mathrm{K}_{2} \mathrm{~S}_{2} \mathrm{O}_{8}\right)$-sodium thiosulfate $\left(\mathrm{Na}_{2} \mathrm{~S}_{2} \mathrm{O}_{3}\right)$ [27], cumene hydroperoxide CHPOTEPA [25], and TBHPO-TEPA [2, 7, 21, 28] are examples. Among these, TBHPO-TEPA initiator is the dominant choice for many researchers due to possible reaction at ambient temperature. Besides this, the presence of protein in NR latex will adversely impact the grafting process. According to previous studies [4, 7], protein can be a free-radical scavenger and terminate the free-radical species of the graft copolymerization. Thus, protein should be removed before graft copolymerization to avoid undesired reactions.

In the present work, graft copolymerization of MMA onto Vietnam DPNR has been studied to obtain high conversion and high grafting efficiency using TBHPO-TEPA as radical initiators at room temperature. Nuclear magnetic resonance $\left({ }^{1} \mathrm{H}\right.$ NMR) and attenuated total reflection/Fourier transform infrared spectroscopy (ATR/FTIR) were used to confirm the structure of the grafted copolymer. Gel permeation chromatography (GPC) measurements were conducted to determine the molecular weight and molecular weight distribution of DPNR and grafted copolymer samples. The thermal and dynamic mechanical properties of the graft copolymer have also been investigated. The grafted NR was afterward vulcanized with sulfur in order to examine the curing and mechanical properties of this copolymer as a commercial material.

\section{Experimental}

\subsection{Chemicals}

2.1.1. Chemicals for Copolymerization. High ammonium natural rubber latex (HANR, 60 wt.\% of dry rubber content rubber) was supplied by Merufa Co., Ltd, Vietnam. Sodium dodecyl sulfate (SDS, 99wt.\%) and MMA (98wt.\%) were purchased from Tokyo Chemical Industry Co., Ltd, Japan. Urea (99wt.\%) was obtained from Nacalai Tesque, Inc (Kyoto, Japan). TEPA (95 wt.\%), TBHPO (68 wt.\%), and other chemical products for copolymerization preparation were purchased from Sigma-Aldrich.

2.1.2. Chemicals for Vulcanization. The sulfur, zinc oxide, stearic acid, accelerators including disulfua mercapthobenzothiazone (DM), mercapthobenzothiazyole $(\mathrm{M})$, and antioxidant RD (TMQ, 2,2,4-Trimethyl-1,2-Dihydroquinoline) were purchased from Nacalai Tesque Inc.

2.2. Preparation of DPNR Latex and Graft Copolymer. DPNR latex was prepared by incubating diluted HANR 60\% dry rubber content (DRC) with $0.1 \mathrm{wt} . \%$ urea in the presence of $1 \mathrm{wt} . \% \mathrm{SDS}$ at $30^{\circ} \mathrm{C}$ for 1 hour and followed by centrifugation at $10,000 \mathrm{rpm}$ for 30 minutes. After centrifugation, the cream fraction was separated and dispersed in $1 \mathrm{wt} . \%$ SDS solution to make $30 \%$ DRC latex. The latex was washed two more times by centrifugation before obtaining the final DPNR, which was dispersed and preserved, respectively, in a 0.9 and 0.8 wt.\% SDS. This SDS concentration level in DPNR latex was used for graft copolymerization with MMA to avoid the coagulation of colloidal suspensions. The removal of proteins in HANR by incubation of the rubber latex with urea has been proved effective in laboratory and batch processing [4].

The DPNR was flushed with nitrogen gas for an hour at $30^{\circ} \mathrm{C}$ to remove any dissolved oxygen in the latex and then graft copolymerized with MMA using a redox initiator system comprising TBHPO and TEPA with mol ratio of $1: 1$. The reaction was kept for 2.5 hours at $400 \mathrm{rpm}$ under $\mathrm{N}_{2}$ atmosphere. Thereafter, the unreacted monomer was removed in a rotary evaporator under reduced pressure, and the obtained emulsion was dried under reduced pressure at $40^{\circ} \mathrm{C}$ for a week. Soxhlet extraction was performed to purify the product. Free-poly methyl methacrylate obtained after extraction with acetone in darkness for 24 hours and drying under reduced pressure for a week. The schematic to perform the graft copolymerization is indicated in Figure 1. 


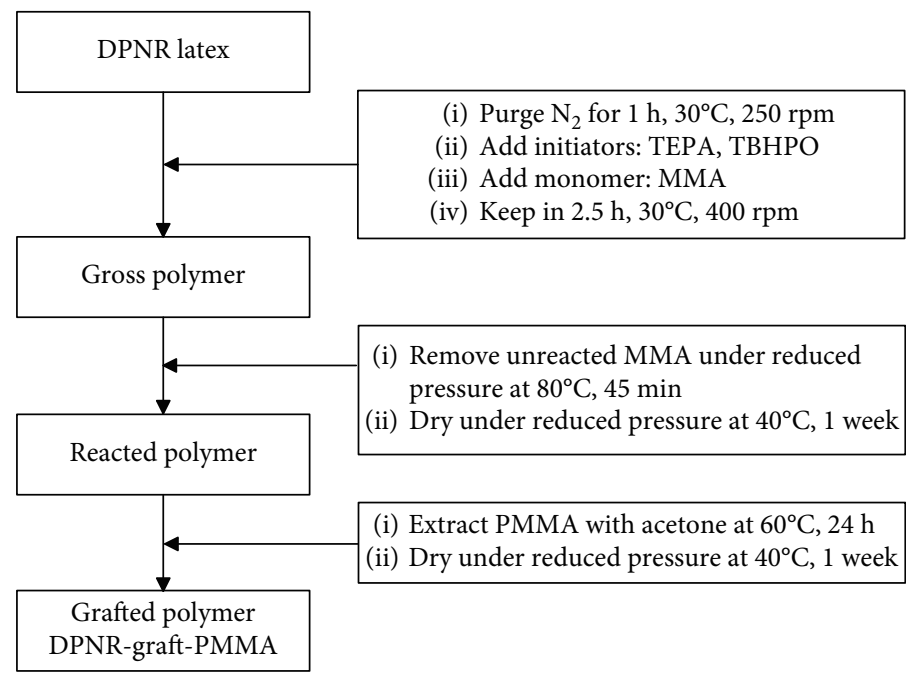

FIGURE 1: Schematic overview of the graft copolymerization of MMA onto DPNR.

TABle 1: Typical recipe used for the vulcanization of rubber samples.

\begin{tabular}{lc}
\hline Ingredients & $\begin{array}{c}\text { Compound } \\
\text { (part per hundred of rubber) }\end{array}$ \\
\hline Rubber* & 100 \\
Stearic acid & 2.5 \\
ZnO & 5 \\
Antioxidant RD & 1.5 \\
Sulfur & 1.7 \\
Disulfua mercapthobenzothiazone & 0.8 \\
(DM) & 0.2 \\
Mercapthobenzothiazyole (M) & \\
*Including DPNR and graft copolymers with different monomer \\
concentrations.
\end{tabular}

2.3. Preparation for Vulcanization of DPNR and DPNRGraft-PMMA. The vulcanization was carried out using an internal mixer (Brabender, Germany). A typical vulcanization recipe can be seen in Table 1 . In the process, we used a mixing chamber of $60 \mathrm{~cm}^{3}$ and the batch size was $50 \pm 5 \mathrm{~g}$. The mixer was operated at a constant rotor speed at $50^{\circ} \mathrm{C}$. The mixing for each batch took place for 13 minutes. Firstly, a rubber sample was added into the chamber and mixed for 6 minutes. Then, stearic acid, $\mathrm{ZnO}$, and $\mathrm{RD}$ were added sequentially. The mixture was afterward mixed additionally for 4.5 minutes. Sulfur, DM, and $M$ were then added into the system and mixed for 2.5 minutes. The mixture was immediately removed from the chamber and left at room temperature for 24 hours. The samples were kept at room temperature for 24 hours and then directly subjected to a rotorless rheometer for defining cure characteristics or cure time for the following pressing step. After that, the produced rubber was pressed in a hot press at $150^{\circ} \mathrm{C}$ and $10 \mathrm{MPa}$ for about 5 minutes (for the DPNR-graft-PMMA samples) or 14 minutes (for the DPNR sample).
After pressing, the obtained rubber sheets were cooled down to room temperature and then cut into small samples with a size according to the ASTM D412-16 standard for each mechanical testing.

2.4. Characterization. Conversion and grafting efficiency (GE) of MMA were calculated by gravimetric method follows these equations [29]:

$$
\text { Conversion, } \%=\frac{\mathrm{m}_{1}-\mathrm{m}_{0}}{\mathrm{~m}} \times 100
$$

$m_{1}$ : weight of product after grafting

$m_{0}$ : weight of DPNR before grafting

$m$ : weight of MMA monomer

$$
\mathrm{GE}, \%=\frac{\mathrm{PP}_{1}-\mathrm{EP}_{0}}{\mathrm{PP}_{1}} \times 100
$$

$\mathrm{PP}_{1}$ : mass of produced polymer.

$\mathrm{EP}_{0}$ : mass of extracted polymer

Proton nuclear magnetic resonance $\left({ }^{1} \mathrm{H}\right.$ NMR) spectra were recorded on a JEOL JNM-ECA $400 \mathrm{MHz}$ spectrometer; samples were swollen with deuterated chloroform. The spectrum was collected for 128 scans.

Attenuated total reflection/Fourier transform infrared spectroscopy (ATR/FTIR, Bruker TENSOR 27 FTIR) was used for the analysis of the NR samples. The frequency region between $4000 \div 400 \mathrm{~cm}^{-1}$ was examined.

Molecular weight and molecular weight distribution of DPNR and DPNR-graft-PMMA samples were measured with a TOSOH GPC consisting of a TOSOH CCPD pump, RI-8012 differential refractometer, and UV-8011 UV detector. The measurement was made at room temperature with the flow rate of the mobile phase, i.e., THF, of $0.5 \mathrm{ml} / \mathrm{min}$. Standard polystyrene, purchased from PSS Polymer Standards Service GmbH (Mainz, Germany), was used as a GPC standard material for calculating the molecular weight. 


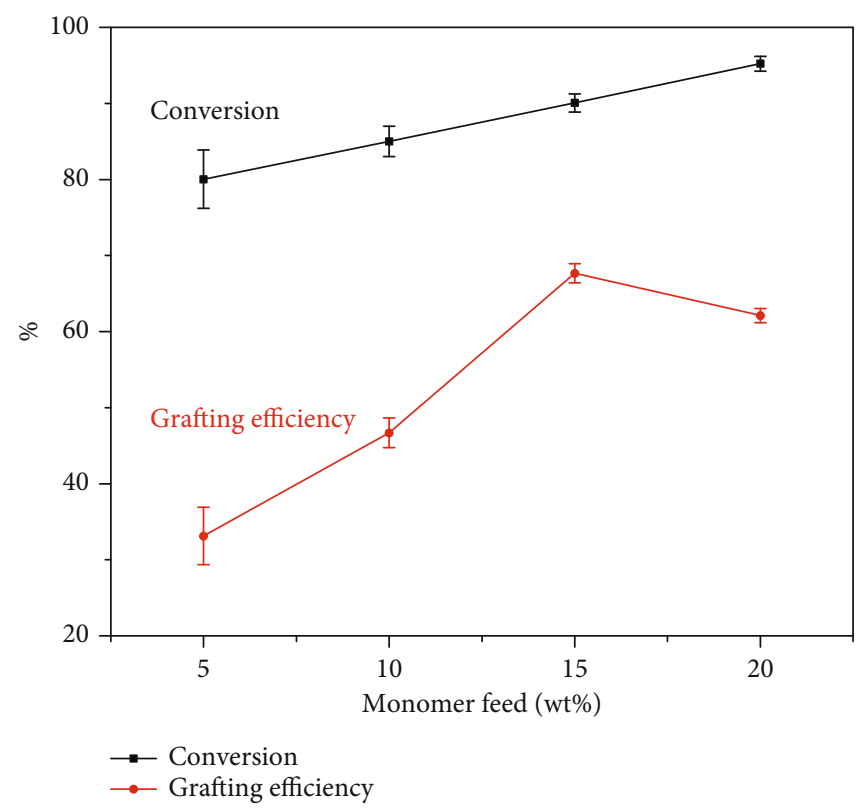

FIGURE 2: Effect of monomer concentration, (wt.\% per kg dried rubber), on graft copolymerization when using MMA.

The dynamic mechanical properties (DMA) were determined using an Anton Paar Physica MCR 302 analyzer. Measurements of the storage modulus, the loss modulus, and the damping factor $\tan \delta$ were performed at $298 \mathrm{~K}$ and frequency range of 0.1 to $16 \mathrm{~Hz}$. Parallel plate geometry of $12 \mathrm{~mm}$ diameter was used. The measurement was carried out within the range of linear viscoelasticity.

Differential scanning calorimetry (DSC) with a DSC 7020 Exstar analyzer was used to measure the glass transition temperature $\left(T_{g}\right)$ of both DPNR and DPNR-graft-PMMA samples. The samples were cooled down to $-90^{\circ} \mathrm{C}$ using liquid nitrogen and heated up to $150^{\circ} \mathrm{C}$ at a heating rate of $10^{\circ} \mathrm{C} / \mathrm{min}$.

Thermal gravimetric analysis (TGA) experiments were carried out using a Shimadzu DTG-60H analyzer under argon atmosphere. The temperature ranged from 30 to $600^{\circ} \mathrm{C}$. The heating rate was $10^{\circ} \mathrm{C} / \mathrm{min}$.

The curing behaviors were assessed by using a Rotorless Rheometer RLR-4 (Japan), at $150 \pm 1^{\circ} \mathrm{C}$, according to ASTM D2084-95. The tensile tests dumbbell-shaped samples were cut from the molded rubber sheets according to ISO 37:2011. Both tensile strength and elongation at break are determined on an Instron 5582 Universal Testing Machine with a crosshead speed of $300 \mathrm{~mm} / \mathrm{min}$. Tear strength is determined on an Instron 5582 Universal Testing Machine with a crosshead speed of $300 \mathrm{~mm} / \mathrm{min}$ according to ISO 23529:2016. Hardness testing machines TFCLOCKGS 709 N (Japan) were used to measure the hardness of DPNR and DPNR-graft-PMMA according to ASTM D2240-15.

\section{Results and Discussion}

3.1. Graft Copolymerization of MMA. Figure 2 shows the effect of monomer concentrations, ranging from 5 to $20 \mathrm{wt} . \%$ per $\mathrm{kg}$ of dried rubber, on the conversion and grafting efficiency of MMA onto DPNR.
It can be seen that both the grafting efficiency and conversion increase with increasing content of MMA up to 15 wt.\%. However, when the monomer content exceeds 15 wt.\%, the GE decreases, while the conversion tends to rise continuously. This might be explained by MMA's homopolymerization becoming dominant over the graft copolymerization of MMA onto the NR particles. At a high MMA concentration (20 wt.\%), monomers are more likely to react with each other than with DPNR's backbone $[7,30]$. The highest grafting efficiency was about $68 \%$ at 15 wt.\% of MMA, and it decreased to $62 \%$ at $20 \mathrm{wt} . \%$ MMA. Therefore, the optimum condition for graft copolymerization of MMA is determined to be $15 \mathrm{wt} . \%$ of MMA. This sample is purified with acetone extraction and subjected for characterization of graft copolymer in the next section.

3.2. Structural Characterization of the Graft Copolymer. Figure 3 exhibits the characteristic absorption bands of DPNR and DPNR grafted with 15 wt.\% MMA. There are three mentioned characteristic peaks attributed to isoprene: the $\mathrm{C}-\mathrm{H}$ stretching vibration in aliphatic $\mathrm{C}-\mathrm{H}$ bond at high frequency $2960 \mathrm{~cm}^{-1}, \mathrm{C}=\mathrm{C}$ bending vibration at $840 \mathrm{~cm}^{-1}$, and $\mathrm{C}-\mathrm{H}$ stretching vibration at $1443 \mathrm{~cm}^{-1}$. A similar type of observation in the IR spectra was already reported [31, 32]. The analysis here focused mainly on the presence of PMMA grafted onto DPNR in general. The bands at 1732 and $1148 \mathrm{~cm}^{-1}$, observed for the DPNR-graft-PMMA $15 \%$ sample, are related to the carbonyl groups $(\mathrm{C}=\mathrm{O}$ stretching) and $\mathrm{C}-\mathrm{O}-\mathrm{C}$ stretching when MMA was grafted on the natural rubber backbone [27]. This proves the presence of the PMMA segment in DPNR-graft-PMMA, and this is a strong evidence to confirm the occurrence of grafting reaction.

The presence of PMMA in natural rubber is also further proved by the ${ }^{1} \mathrm{H}-\mathrm{NMR}$ method using $\mathrm{CDCl}_{3}$ as a solvent of the measurement. In Figure 4, the characteristic signals of cis-1,4-isoprene units appeared at 1.67, 1.93, and $4.95 \mathrm{ppm}$. 


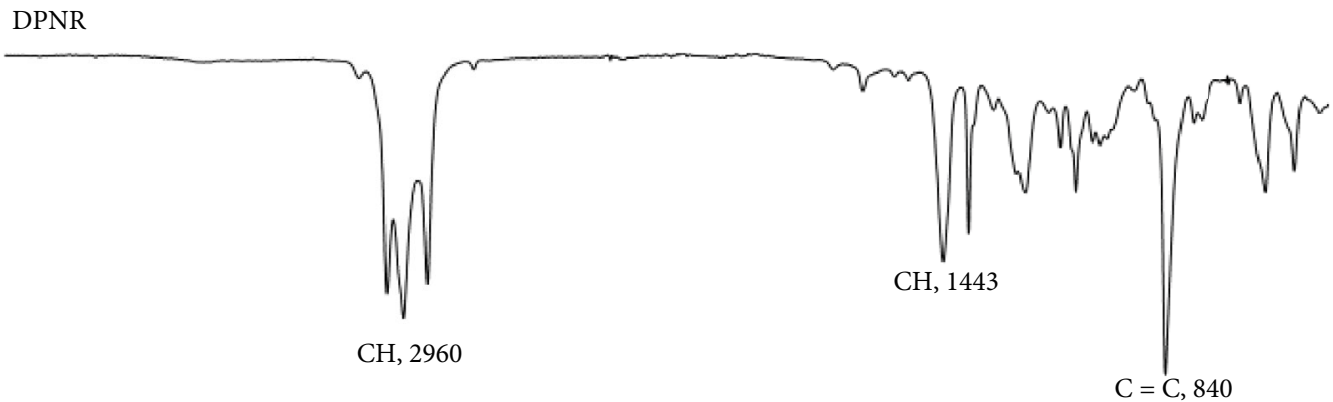

DPNR-graft-PMMA

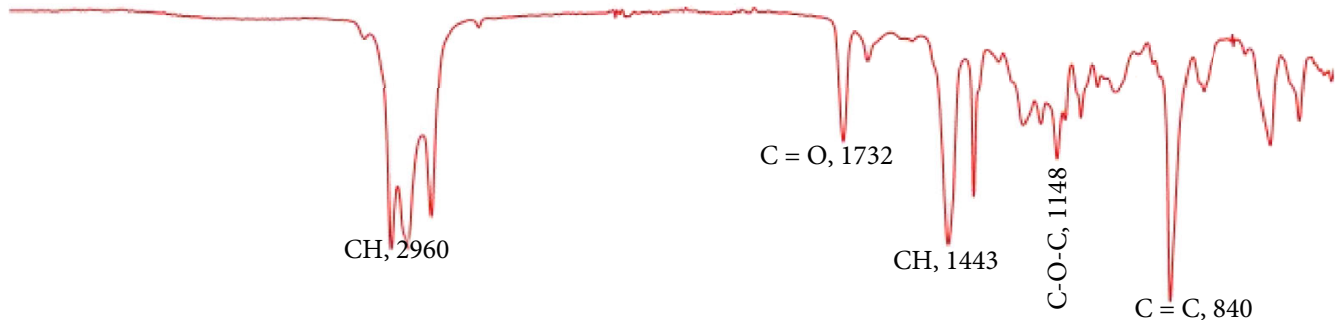

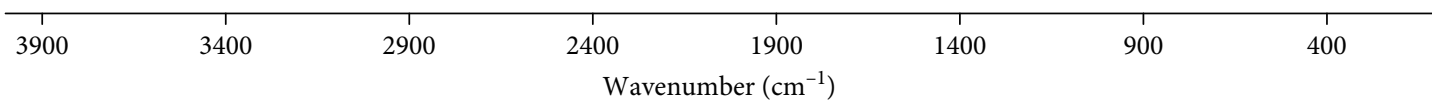

Figure 3: The FTIR spectra of DPNR and DPNR-graft-PMMA 15 wt.\%.<smiles>CC/C(C)=C\[C@@H](C)CC(C)(C)C(=O)OC</smiles>
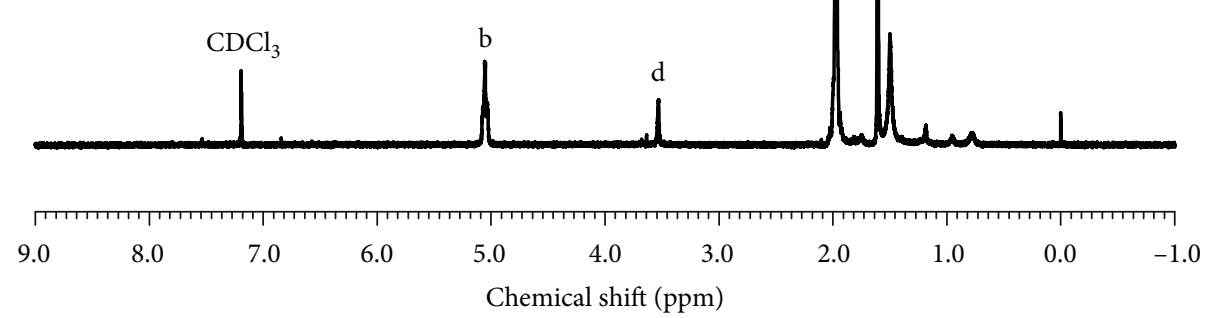

Figure 4: ${ }^{1} \mathrm{H}-\mathrm{NMR}$ spectra of DPNR-graft-PMMA 15 wt.\%.

These can be attributed to the methyl, methylene, and unsaturated methine protons of cis-1,4-isoprene units, respectively $[33,34]$. On the other hand, an additional signal at about $3.58 \mathrm{ppm}$ was assigned to the protons of $\mathrm{O}-\mathrm{CH}_{3}$ of the grafted PMMA [27]. This is in agreement with above FTIR assignments. Therefore, the combination of ${ }^{1} \mathrm{H}$ NMR data and FTIR results surely confirms the occurrence of grafting polymerization of MMA onto DPNR.

3.3. Molecular Weight Distribution. Figure 5 shows the molecular weight distribution for DPNR and DPNR-graftPMMA 15 wt.\%. The appearance of a sharp peak at about 


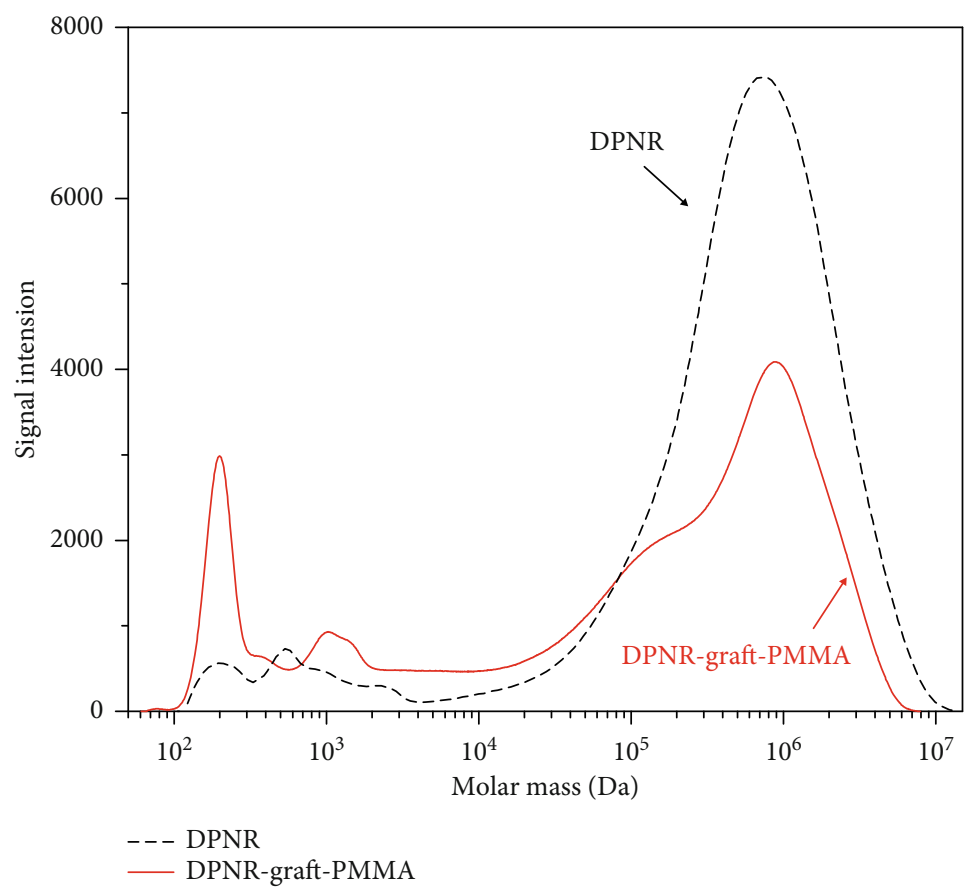

Figure 5: Molecular weight distribution for DPNR and DPNR-graft-PMMA 15 wt.\%.

TABle 2: $M_{n}, M_{w}$, and PDI for DPNR and DPNR-graft-PMMA 15 wt.\%.

\begin{tabular}{lccc}
\hline Samples & $M_{n}$ & $M_{w}$ & PDI $=M_{w} / M_{n}$ \\
\hline DPNR & $7.4769 \times 103$ & $8.8145 \times 105$ & $1.1789 \times 102$ \\
DPNR-g-PMMA 15 wt.\% & $1.9238 \times 103$ & $5.4952 \times 105$ & $2.8565 \times 102$ \\
\hline
\end{tabular}

$3 \times 10^{3} \mathrm{Da}$ implies that new particles were formed during the graft-copolymerization. This is evident from the formation of various components in the resulting materials, which are grafted PMMA and PMMA homopolymer. The Gaussian distribution is related to DPNR. After the graftcopolymerization of MMA, the particle size distribution became multimodal. Table 2 shows the weight averaged molecular weight $\left(M_{w}\right)$, number averaged molecular weight $\left(M_{n}\right)$, and polydispersity $\mathrm{PDI}\left(M_{w} / M_{n}\right)$ for the uncrosslinked polymers in the sol fraction [35]. PDI was found to be $1.1789 \times 10^{2}$. It was too high for the obtained polymer. This may be purified by fractional precipitation to remove the low molar mass of residues [36, 37]. In the presence of TBHPO and TEPA initiators, chain session or chain degradation could possibly take place. The shoulder peak at about $10^{5} \mathrm{Da}$ could indicate the formation of unstable molecules, which cannot polymerize. The uncross-linked polymers in the sol fraction gave lower $M_{n}$ and $M_{w}$ values than those before the graft copolymerization. This result may suggest that various molecules with different chain lengths of chain appeared in DPNR-graft-PMMA [27]. In terms of practical applications, it is vital to do the cure step for the graft copolymerization. It will be presented below.

3.4. Thermal Properties. The glass transition temperatures $\left(T_{g}\right)$ of the materials were investigated with differential scan- ning calorimetry (DSC). The curves for DPNR and DPNRgraft-PMMA with 15 wt.\% MMA are shown in Figure 6.

There was only one $T_{g}$ observed at $-62.5^{\circ} \mathrm{C}$, which corresponds to the cis-1,4 polyisoprene structures of the DPNR, which has also been reported in Derouet's study [23]. It can be seen that after graft copolymerization, the $T_{g}$ of graft copolymer slightly shifts to $-60.5^{\circ} \mathrm{C}$ due to the presence of grafted PMMA chain on the NR molecules. The appearance of PMMA chain may result in the stiffening or the increased interchain interaction between polar functional groups in the graft copolymer [30].

TGA curves of DPNR and the graft copolymer are shown in Figure 7. It can be seen that the degradation of DPNR occurs vastly at the decomposition temperature $\left(T_{d}\right)$ of $365.36^{\circ} \mathrm{C}$. However, DPNR-graft-PMMA showed a higher decomposition temperature at $373.77^{\circ} \mathrm{C}$. This could be ascribed in terms of decreasing levels of reactive unsaturated backbone and therefore less susceptibility to degradation. Thus, it is clear that the MMA grafting improved the thermal stability of the DPNR. This observation is in agreement with the thermal degradation of modified natural rubber with other vinyl monomers [5, 32, 34, 38, 39].

3.5. Dynamics Mechanical Properties of DPNR and DPNRGraft-PMMA. Figure 8 illustrates the frequency dependence of storage modulus $G^{\prime}$ at rubbery plateau region for DPNR 


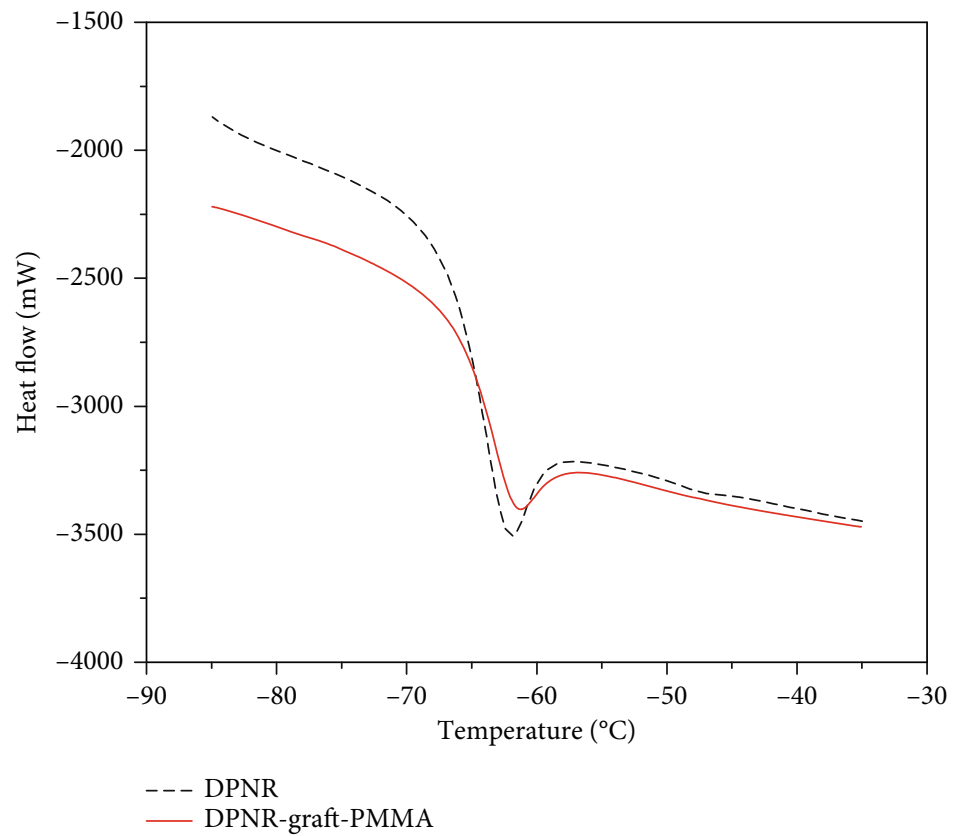

Figure 6: DSC curves of DPNR and DPNR-graft-PMMA 15 wt.\%.
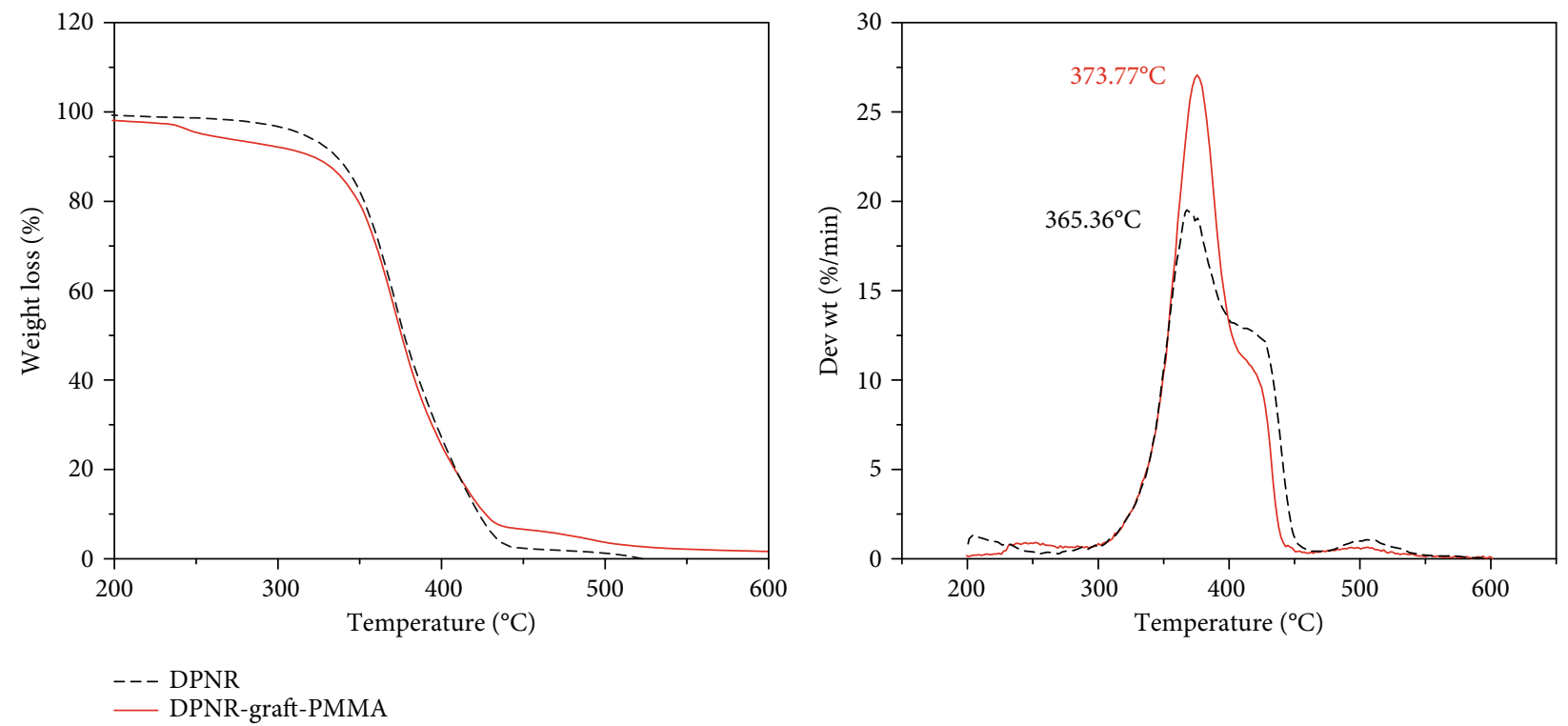

FIGURE 7: TGA thermograms under argon atmosphere of DPNR and DPNR-graft-PMMA 15 wt.\%.

and DPNR-graft-PMMA 15 wt.\%. The value region of $\mathrm{G}^{\prime}$ for DPNR was about $0.1 \mathrm{MPa}$, similar to values reported in literature $[28,29]$. By graft copolymerization of MMA onto DPNR, the value of $\mathrm{G}^{\prime}$ of DPNR-graft-PMMA $15 \mathrm{wt} . \%$ was increased double at high-frequency region. Hence, it is proved that graft copolymerization of MMA onto NR increases the ability of natural rubber to store deformation energy [29].

Figure 9 shows the loss modulus $\left(\mathrm{G}^{\prime \prime}\right)$ in the plateau region versus the frequency for DPNR and DPNR-graftPMMA samples. The loss modulus value of DPNR was $10^{4} \mathrm{~Pa}$. We can readily demonstrate that this value is typical for conventional uncross-linked rubber and is similar to the $\mathrm{G}^{\prime \prime}$ of NR previously reported $[29,40]$. In addition, the loss modulus decreases as the frequency increases [41]. In contrast, the loss modulus of DPNR-graft-MMA increases gradually with the frequency, indicating its different behavior compared to ordinary rubber. DPNR-graft-PMMA exhibits both entropic elasticity and energetic elasticity $[29,41]$.

Figure 10 plots the loss tangent $(\tan \delta)$ versus the frequency in the plateau region for DPNR and DPNR-graftPMMA 15 wt.\%. The values of $\tan \delta$ for DPNR decrease with increasing of frequency. Tan $\delta$ for the grafted DPNR is almost independent on the frequency in the low-frequency 


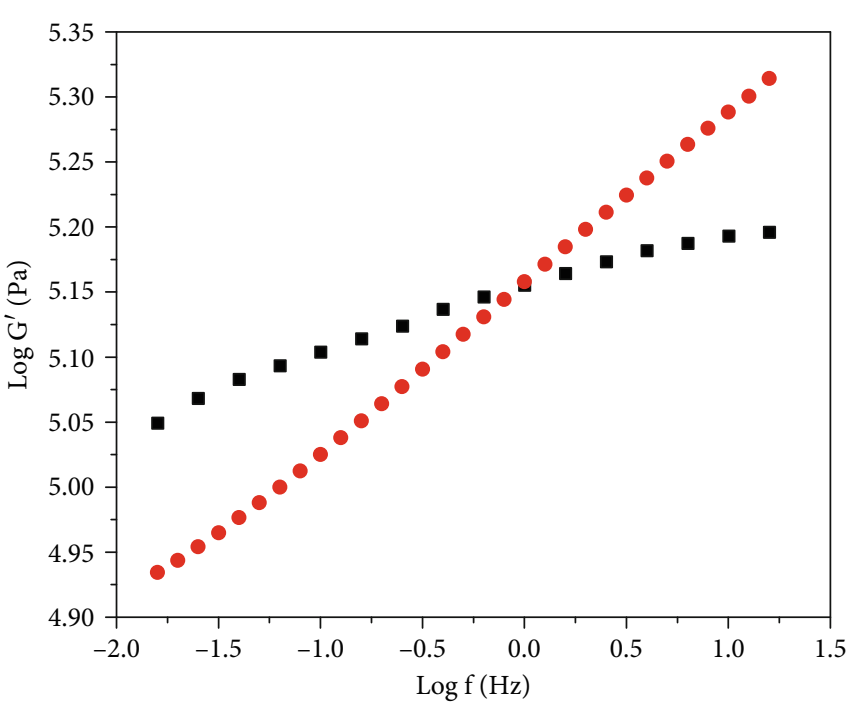

- DPNR

- DPNR-graft-PMMA

Figure 8: Storage modulus $\left(G^{\prime}\right)$ in the plateau region vs frequency at $298 \mathrm{~K}$ for DPNR and DPNR-graft-PMMA $15 \mathrm{wt} . \%$.

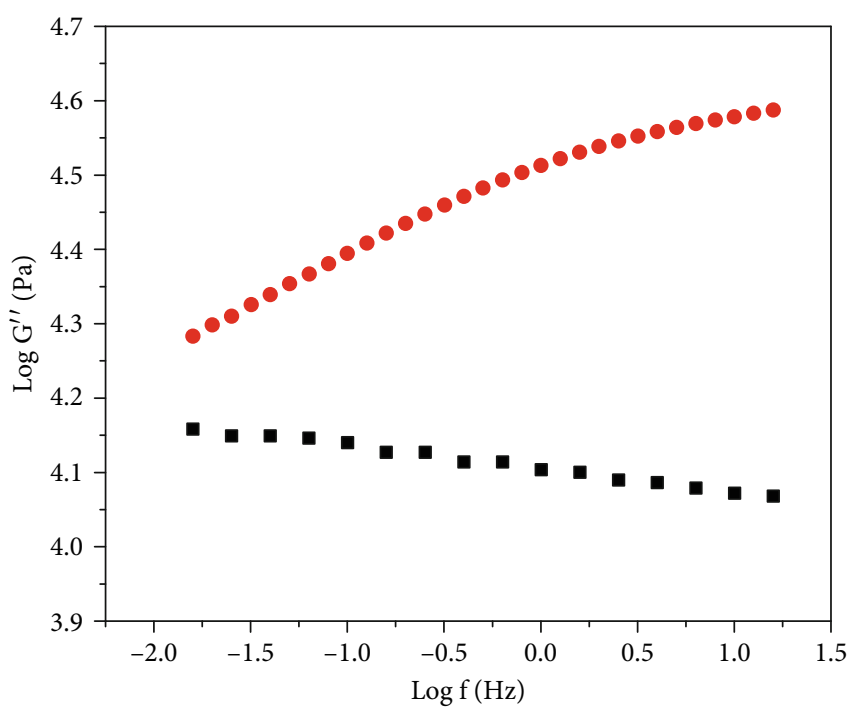

- DPNR

- DPNR-graft-PMMA

FIGURE 9: Loss modulus $\left(G^{\prime \prime}\right)$ in the plateau region vs frequency at $298 \mathrm{~K}$ for DPNR and DPNR-graft-PMMA 15 wt.\%.

region but decreases slightly in the high-frequency region. This observation agrees with the frequency dependency of the $G^{\prime}$ and $G^{\prime \prime}$. The trend of $\tan \delta$ with frequency also demonstrates that DPNR-graft-PMMA generates entropic elasticity [41] due to the behavior of DPNR, and energetic elasticity due to the grafting of MMA.

\subsection{Cure Behaviors and Properties of Vulcanized}

DPNR-Graft-PMMA. The cure characteristics of DPNRgraft-PMMA were determined via values of the scorch time $\left(t_{s 2}\right)$, cure time $\left(t_{c 90}\right)$, minimum torque $\left(M_{L}\right)$, maximum tor-

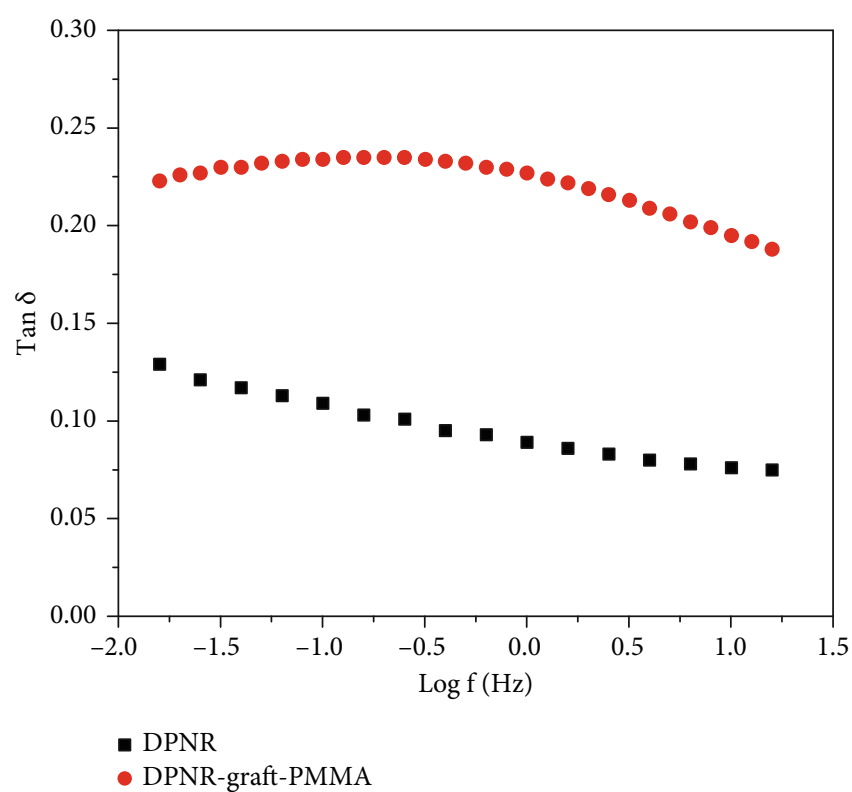

FIgURE 10: Loss tangent in the plateau region vs frequency at $298 \mathrm{~K}$ for DPNR and DPNR-graft-PMMA 15 wt.\%.

que $\left(M_{H}\right)$, torque difference $\left(M_{H}-M_{L}\right)$, and cure rate index (CRI) according to ASTM D5289, as shown in Table 3. The CRI is related to the speed at which the cure reaction occur and was calculated as follows [42]:

$$
\mathrm{CRI}=100 /\left(t_{c 90}-t_{s 2}\right)
$$

The effects of the initial amount of MMA on the curing characteristics of DPNR-graft-PMMA were examined separately using a moving die rheometer. The values of the scorch time $\left(t_{s 2}\right)$ and cure time $\left(t_{c 90}\right)$ of DPNR-graft-PMMA compounds were found to be much smaller than virgin DPNR, indicating that the presence of MMA in DPNR's backbone could accelerate vulcanization during the induction period of curing and shorten the optimum cure time. This is confirmed by an increase in CRI for higher degree grafting. Higher degrees of grafting were caused by crosslinking reactions via the sulfidic linkages as well as reactions of carbonyl groups between MMA molecules [43].

Figure 11 shows the influence of the weight concentration of MMA used in the graft copolymerization on torques. Theoretically, the torque relates to the shear modulus or the stiffness of the rubber materials. As can be seen in Table 3, the minimum torque $M_{L}$ and maximum torque $M_{H}$ of all DPNR-graft-PMMA compounds have higher values than the virgin DPNR compounds. This might be caused by an increasing chemical interaction between the DPNR backbone and MMA, causing limited mobility for DPNR [44]. The maximum torque $\left(M_{H}\right)$ and delta torque $\left(M_{H}-M_{L}\right)$ are significantly related to the amount of crosslinking, crosslink density, and interactions in the rubber vulcanization. The DPNR-graft-PMMA 15 wt.\% compound exhibited the highest $M_{H}$. The increase in $\left(M_{H}-M_{L}\right)$ elucidated an increased crosslink density in compounds by crosslinking from sulfidic linkages and polar MMA as mentioned before. 
TABLE 3: The cure characteristics for DPNR and DPNR-graft-PMMA samples.

\begin{tabular}{lcccccc}
\hline Samples & $M_{L}(\mathrm{dN} . \mathrm{m})$ & $M_{H}(\mathrm{dN} . \mathrm{m})$ & $M_{H}-M_{L}(\mathrm{dN} . \mathrm{m})$ & $t_{s 2}(\min )$ & $t_{c 90}(\mathrm{~min})$ & $\mathrm{CRI}\left(\mathrm{min}^{-1}\right)$ \\
\hline DPNR & 1.95 & 5.71 & 3.76 & 5.13 & 10.89 & 26.52 \\
DPNR-g-PMMA 5 wt.\% & 3.22 & 8.67 & 5.45 & 0.70 & 2.89 \\
DPNR-g-PMMA 10 wt.\% & 3.02 & 8.85 & 5.83 & 0.82 & 3.04 \\
DPNR-g-PMMA 15 wt.\% & 2.67 & 9.02 & 6.35 & 0.82 & 2.94 \\
DPNR-g-PMMA 20 wt.\% & 3.03 & 8.98 & 5.95 & 0.77 & 2.89 \\
\hline
\end{tabular}

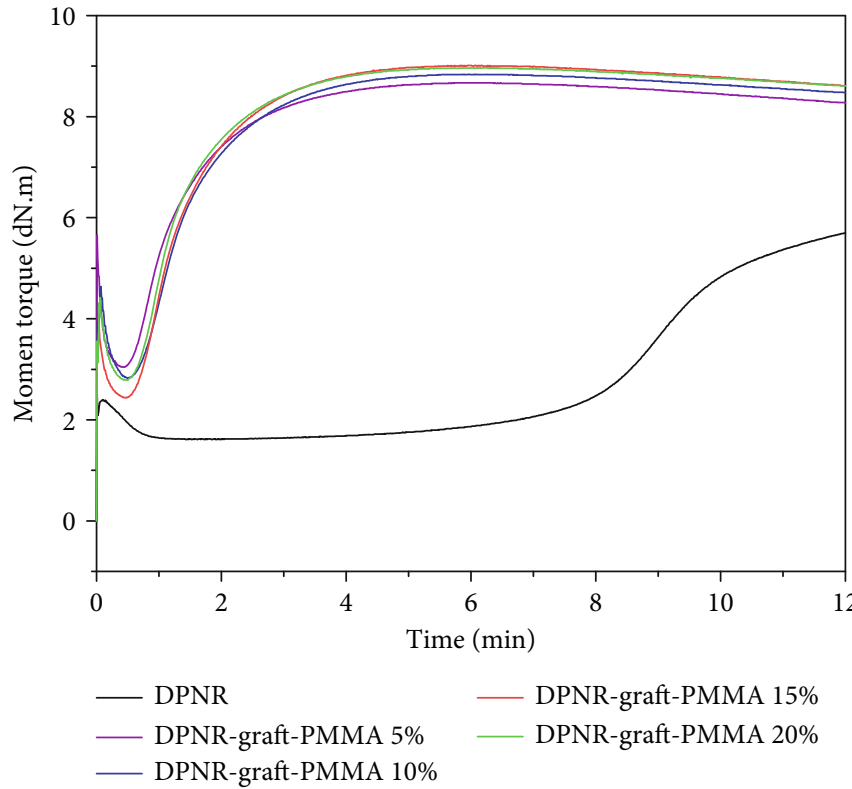

FIgURE 11: Rheographs for DPNR-graft-PMMA with different contents of MMA.

TABLE 4: Mechanical properties for vulcanized samples.

\begin{tabular}{lcccc}
\hline Samples & Tensile strength $(\mathrm{MPa})$ & Elongation at break, \% & Tear strength (kN/m) & Hardness (shore A) \\
\hline DPNR & $8.2 \pm 0.6$ & $660.0 \pm 17.1$ & $28.0 \pm 1.3$ & $41.9 \pm 1.6$ \\
DPNR-g-PMMA 5 wt.\% & $12.3 \pm 0.5$ & $431.3 \pm 20.0$ & $43.9 \pm 2.4$ & $35.5 \pm 0.4$ \\
DPNR-g-PMMA 10 wt.\% & $13.8 \pm 0.7$ & $420.0 \pm 19.1$ & $46.6 \pm 2.1$ & $36.1 \pm 0.6$ \\
DPNR-g-PMMA 15 wt.\% & $15.8 \pm 1.1$ & $379.0 \pm 23.3$ & $46.8 \pm 2.5$ & $37.3 \pm 0.3$ \\
DPNR-g-PMMA 20 wt.\% & $16.1 \pm 0.9$ & $262.9 \pm 18.9$ & $41.7 \pm 0.4$ \\
\hline
\end{tabular}

The mechanical properties of copolymers and DPNR vulcanizates are illustrated in Table 4 . The tensile strength and tear strength (at break) of DPNR vulcanizate increased significantly with the incorporation of MMA, in agreement with previous literature [45]. The hardness for DPNR-graftPMMA was 1.5-2 times higher than for DPNR. Whereas in elongation at break, the values for DPNR-graft-PMMA compounds were much lower than those for DPNR. All those trends could be the result of interaction between DPNR and MMA, which may lead to improved physical entanglement and a stiffer structure $[42,45]$. In addition, it can be seen that for MMA feeds of 15 wt.\% MMA and higher, the tensile and tear strength rose negligibly, while the elongation at break decreased remarkably and the hardness value increased significantly.
In conclusion, by introducing MMA segment onto DPNR molecules, the material becomes harder after vulcanization, and the curing times are shorter. However, the small differences observed in cure characteristics for the studied vulcanized DPNR-graft-PMMA samples indicated that the difference in amount of MMA does not have a significant effect on the torque of sulfur vulcanized DPNR-graft-PMMA.

\section{Conclusions}

The graft copolymerization of MMA onto DPNR in latex stage with TBHPO/TEPA as radical initiators was performed successfully. This was confirmed by FTIR as well as by ${ }^{1} \mathrm{H}$ NMR spectra, where the presence of MMA on the synthesized material was observed. The grafted DPNR proved to 
have more stable thermal properties, demonstrated by increased values in both $T_{g}$ and $T_{d}$. It was revealed that the thermal properties and the rigidity of graft copolymer, DPNR-graft-PMMA, were improved after graft copolymerization. The DPNR-graft-PMMA with 15 wt.\% MMA exhibited optimal properties in terms of practical application. By introducing PMMA into the NR molecule, the storage modulus of NR also increased remarkably. Natural rubber was vulcanized faster and more efficiently than DPNR due to the presence of polar functional groups. The sulfurvulcanized DPNR-graft-PMMA exhibited better mechanical properties than cured DPNR.

\section{Data Availability}

The data used to support the findings of this study are included within the article.

\section{Conflicts of Interest}

The authors declare that they have no conflicts of interest.

\section{Acknowledgments}

This research is funded by the Hanoi University of Science and Technology (HUST) under project number T2018-TĐ001. The authors are grateful to Nigel Van de Velde for the valuable comments and corrections during revision of the manuscript.

\section{References}

[1] S. Kohjiya, Chemistry, Manufacture and Applications of Natural Rubber, Elsevier, 2014.

[2] T. Dung, N. Nhan, N. Thuong et al., "Modification of Vietnam natural rubber via graft copolymerization with styrene," Journal of the Brazilian Chemical Society, vol. 28, no. 4, pp. 669675, 2016.

[3] E. Warren-Thomas, P. M. Dolman, and D. P. Edwards, "Increasing demand for natural rubber necessitates a robust sustainability initiative to mitigate impacts on tropical biodiversity," Conservation Letters, vol. 8, no. 4, pp. 230-241, 2015.

[4] S. Kawahara, W. Klinklai, H. Kuroda, and Y. Isono, "Removal of proteins from natural rubber with urea," Polymers for Advanced Technologies, vol. 15, no. 4, pp. 181-184, 2004.

[5] Y. Cui, Y. Xiang, Y. Xu et al., "Poly-acrylic acid grafted natural rubber for multi-coated slow release compound fertilizer: Preparation, properties and slow-release characteristics," International Journal of Biological Macromolecules, vol. 146, pp. 540-548, 2020.

[6] P. Phinyocheep, "Chemical modification of natural rubber (NR) for improved performance," in Chemistry, manufacture and applications of natural rubber, pp. 68-118, Elsevier, 2014.

[7] S. Kawahara, T. Kawazura, T. Sawada, and Y. Isono, "Preparation and characterization of natural rubber dispersed in nanomatrix," Polymer, vol. 44, no. 16, pp. 4527-4531, 2003.

[8] P. Suksawad, Y. Yamamoto, and S. Kawahara, "Preparation of thermoplastic elastomer from natural rubber grafted with polystyrene," European Polymer Journal, vol. 47, no. 3, pp. 330-337, 2011.
[9] V. R. Vijay, A. M. Anitha, and A. R. R. Menon, "Studies on blends of natural rubber and butadiene rubber containing silica - Organomodified kaolin hybrid filler systems," Polymer, vol. 89, pp. 135-142, 2016.

[10] W.Chueangchayaphan, V.Tanrattanakul, N. Chueangchayaphan, S. Muangsap, and W. Borapak, "Synthesis and thermal properties of natural rubber grafted with poly (2-hydroxyethyl acrylate)," Journal of Polymer Research, vol. 24, no. 7, p. 107, 2017.

[11] N. Hariwongsanupab, S. Thanawan, T. Amornsakchai, M.-F. Vallat, and K. Mougin, "Improving the mechanical properties of short pineapple leaf fiber reinforced natural rubber by blending with acrylonitrile butadiene rubber," Polymer Testing, vol. 57, pp. 94-100, 2017.

[12] J.-B.-D. François and E. Fleury, "Method for modifying a natural rubber, and modified natural rubber," U.S. Patent Application No 16/068,939, 2019.

[13] K. K. Wei, T. P. Leng, Y. C. Keat, H. Osman, and M. S. M. Rasidi, "The potential of natural rubber (NR) in controlling morphology in two-matrix epoxy/NR/graphene nanoplatelets (GNP) systems," Polymer Testing, vol. 77, article 105905, 2019.

[14] N. K. Singha, P. De, and S. Sivaram, "Homogeneous catalytic hydrogenation of natural rubber using $\mathrm{RhCl}(\mathrm{PPh} 3)$ 3," Journal of Applied Polymer Science, vol. 66, no. 9, pp. 1647-1652, 1997.

[15] A. Mahittikul, P. Prasassarakich, and G. L. Rempel, "Diimide hydrogenation of natural rubber latex," Journal of Applied Polymer Science, vol. 105, no. 3, pp. 1188-1199, 2007.

[16] A. Mahittikul, P. Prasassarakich, and G. L. Rempel, "Noncatalytic hydrogenation of natural rubber latex," Journal of Applied Polymer Science, vol. 103, no. 5, pp. 2885-2895, 2007.

[17] N. Hinchiranan, P. Prasassarakich, and G. L. Rempel, "Hydrogenation of natural rubber in the presence of $\mathrm{OsHCl}$ (CO)(O2)(PCy3) 2: kinetics and mechanism," Journal of Applied Polymer Science, vol. 100, no. 6, pp. 4499-4514, 2006.

[18] M. Arroyo, M. Lopezmanchado, J. Valentin, and J. Carretero, "Morphology/behaviour relationship of nanocomposites based on natural rubber/epoxidized natural rubber blends," Composites Science and Technology, vol. 67, no. 7-8, pp. 1330-1339, 2007.

[19] F. Okieimen and I. Urhoghide, "Studies on miscibility of poly (vinyl chloride) with natural rubber-graft-polyacrylonitrile and natural rubber-graft-poly (methyl methacrylate)," Journal of Applied Polymer Science, vol. 59, no. 11, pp. 1803-1808, 1996.

[20] L. Thiraphattaraphun, S. Kiatkamjornwong, P. Prasassarakich, and S. Damronglerd, "Natural rubber-g-methyl methacrylate/poly (methyl methacrylate) blends," Journal of Applied Polymer Science, vol. 81, no. 2, pp. 428-439, 2001.

[21] C. Nakason, A. Kaesaman, and N. Yimwan, "Preparation of graft copolymers from deproteinized and high ammonia concentrated natural rubber latices with methyl methacrylate," Journal of Applied Polymer Science, vol. 87, no. 1, pp. 68-75, 2003.

[22] S. Zhang, L. Cao, F. Shao, L. Chen, J. Jiao, and W. Gao, "Grafting of methyl methacrylate onto natural rubber in supercritical carbon dioxide," Polymers for Advanced Technologies, vol. 19, no. 1, pp. 54-59, 2008.

[23] D. Derouet, Q. N. Tran, and J.-L. Leblanc, "Physical and mechanical properties of poly(methyl methacrylate)-grafted 
natural rubber synthesized by methyl methacrylate photopolymerization initiated by N,N-diethyldithiocarbamate functions previously created on natural rubber chains," Journal of Applied Polymer Science, vol. 112, no. 2, pp. 788-799, 2009.

[24] H. Afifi and A. A. El-Wakil, "Study of the effect of natural rubber-graft-maleic anhydride (NR-g-MA) on the compatibility of NR-NBR blends using the ultrasonic technique," Polymer-Plastics Technology and Engineering, vol. 47, no. 10, pp. 1032-1039, 2008.

[25] W. Arayapranee, P. Prasassarakich, and G. L. Rempel, "Synthesis of graft copolymers from natural rubber using cumene hydroperoxide redox initiator," Journal of Applied Polymer Science, vol. 83, no. 14, pp. 2993-3001, 2002.

[26] B. George, S. N. Maiti, and I. K. Varma, "Graft copolymerization of methyl methacrylate on to natural rubber: effect of polymerization conditions on particle morphology," Journal of Elastomers \& Plastics, vol. 38, no. 4, pp. 319-331, 2016.

[27] T. Kochthongrasamee, P. Prasassarakich, and S. Kiatkamjornwong, "Effects of redox initiator on graft copolymerization of methyl methacrylate onto natural rubber," Journal of Applied Polymer Science, vol. 101, no. 4, pp. 25872601, 2006.

[28] T. H. Nguyen, Q. V. Do, A. D. Tran, and S. Kawahara, "Preparation of hydrogenated natural rubber with nanomatrix structure," Polymers for Advanced Technologies, vol. 31, no. 1, pp. 86-93, 2019.

[29] Y. Yamamoto, P. Suksawad, N. Pukkate, T. Horimai, O. Wakisaka, and S. Kawahara, "Photoreactive nanomatrix structure formed by graft-copolymerization of 1, 9-nonandiol dimethacrylate onto natural rubber," Journal of Polymer Science Part A: Polymer Chemistry, vol. 48, no. 11, pp. 24182424, 2010.

[30] P. Saramolee, N. Lopattananon, and K. Sahakaro, "Preparation and some properties of modified natural rubber bearing grafted poly (methyl methacrylate) and epoxide groups," European Polymer Journal, vol. 56, pp. 1-10, 2014.

[31] C. Nakason, A. Kaesaman, and P. Supasanthitikul, "The grafting of maleic anhydride onto natural rubber," Polymer Testing, vol. 23, no. 1, pp. 35-41, 2004.

[32] N. H. Yusof, K. Kosugi, T. K. Song, and S. Kawahara, "Preparation and characterization of poly (stearyl methacrylate) grafted natural rubber in latex stage," Polymer, vol. 88, pp. 43-51, 2016.

[33] P. C. de Oliveira, A. M. de Oliveira, A. Garcia, J. C. de Souza Barboza, C. A. de Carvalho Zavaglia, and A. M. dos Santos, "Modification of natural rubber: a study by $1 \mathrm{H}$ NMR to assess the degree of graftization of polyDMAEMA or polyMMA onto rubber particles under latex form in the presence of a redox couple initiator," European Polymer Journal, vol. 41, no. 8, pp. 1883-1892, 2005.

[34] E. Kalkornsurapranee, K. Sahakaro, A. Kaesaman, and C. Nakason, "Influence of reaction volume on the properties of natural rubber-g-methyl methacrylate," Journal of Elastomers \& Plastics, vol. 42, no. 1, pp. 17-34, 2010.

[35] Y. Fukushima, S. Kawahara, and Y. Tanaka, "Synthesis of graft copolymers from highly deproteinised natural rubber," Journal of Rubber Research (Malaysia), vol. 1, no. 3, pp. 154-166, 1998.

[36] B. Hazer, E. Ayyıldız, M. Eren, H. S. Canbay, and R. D. Ashby, "Autoxidized oleic acid bifunctional macro peroxide initiators for free radical and condensation polymerization. Synthesis and characterization of multiblock copolymers," Journal of
Polymers and the Environment, vol. 27, no. 11, pp. 25622576, 2019.

[37] B. Wu, R. W. Lenz, and B. Hazer, "Polymerization of methyl methacrylate and its copolymerization with $\varepsilon$-caprolactone catalyzed by isobutylalumoxane catalyst," Macromolecules, vol. 32, no. 20, pp. 6856-6859, 1999.

[38] S. Benmesli and F. Riahi, "Dynamic mechanical and thermal properties of a chemically modified polypropylene/natural rubber thermoplastic elastomer blend," Polymer Testing, vol. 36, pp. 54-61, 2014.

[39] P. Wongthong, C. Nakason, Q. Pan, G. L. Rempel, and S. Kiatkamjornwong, "Modification of deproteinized natural rubber via grafting polymerization with maleic anhydride," European Polymer Journal, vol. 49, no. 12, pp. 4035-4046, 2013.

[40] T. A. Dung, N. T. Nhan, N. T. Thuong et al., "Dynamic mechanical properties of Vietnam modified natural rubber via grafting with styrene," International Journal of Polymer Science, vol. 2017, 8 pages, 2017.

[41] Y. Zhou, Y. Yamamoto, and S. Kawahara, "Determination of a suitable condition of graft copolymerization of vinyltriethoxysilane onto Nr to form nanomatrix structure," Rubber Chemistry and Technology, vol. 91, no. 4, pp. 767-775, 2018.

[42] F. Deng, Y. Zhang, X. Ge, M. Li, X. Li, and U. R. Cho, "Graft copolymers of microcrystalline cellulose as reinforcing agent for elastomers based on natural rubber," Journal of Applied Polymer Science, vol. 133, no. 9, 2016.

[43] W. Chueangchayaphan, N. Chueangchayaphan, V. Tanrattanakul, and S. Muangsap, "Influences of the grafting percentage of natural rubber-graft-poly (2-hydroxyethyl acrylate) on properties of its vulcanizates," Polymer International, vol. 67, no. 6, pp. 739-746, 2018.

[44] C. Nakason, W. Pechurai, K. Sahakaro, and A. Kaesaman, "Rheological, thermal, and curing properties of natural rubber-g-poly (methyl methacrylate)," Journal of Applied Polymer Science, vol. 99, no. 4, pp. 1600-1614, 2006.

[45] E. Kalkornsurapranee, W. Yung-Aoon, B. Thongnuanchan, A. Thitithammawong, C. Nakason, and J. Johns, "Influence of grafting content on the properties of cured natural rubber grafted with PMMAs using glutaraldehyde as a cross-linking agent," Advances in Polymer Technology, vol. 37, no. 5, pp. 1478-1485, 2018. 